\title{
Anagram versus word-fragment solution: A comparison of implicit-memory measures
}

\author{
LAWRENCE M. SCHOEN, ELIZABETH CIOFALO, and ELIZABETH RUDOW \\ New College of the University of South Florida, Sarasota, Florida
}

(Richard J. Harris, Sponsor)

\begin{abstract}
Previous experiments have revealed that word-completion tasks (both word stem and word fragment) are powerful measures of implicit memory. The present study compared the results obtained using word fragments with a new measure, anagram solution. It may be argued that both measures are tapping data-driven processes in memory, but the strategies necessary for these two types of completion tasks are intuitively quite different. The results obtained by this comparison reveal no significant differences between the two measures. Further ramifications of these findings in implicit-memory testing are discussed.
\end{abstract}

Experiments in implicit memory have generally used word-stem completion (e.g., Graf, Squire, \& Mandler, 1984; Schacter \& Graf, 1986) or word-fragment completion (cf. Gardiner, 1988; Roediger \& Blaxton, 1987) as the measure of choice. These word-completion effects are quite robust and can be obtained very easily (Schoen, 1988). The present study was a slight departure from these procedures, using anagram-solution rate as the measure of implicit memory.

\section{METHOD}

\section{Subjects}

The subjects were 38 students enrolled in evening courses at the Sarasota campus of the University of South Florida and were paid between three and five dollars for their participation. The subjects were assigned randomly to one of two groups within either the anagram or word-fragment conditions.

\section{Materials}

Eighty-seven five-letter words were selected from the pool of unique two-letter word fragments developed by Gibson and Watkins (1988). These particular items were chosen for having only one possible meaningful anagram. The words were then divided into 31 filler items and 56 test items. Unique anagrams and two-letter word fragments were generated for all 87 items. The individual filler items were permitted to have one or more letters in common, whereas each of the test items was composed of five different letters. The 56 test items were then sorted randomly into two sets of 28 words.

\section{Procedure}

All subjects were presented with one of two series of 28 words for a duration of $10 \mathrm{sec}$ per item. These words represented half of the test items described above. One group of subjects in the anagram condition was presented one series of words, and a second group in the same condition received the remaining 28 items. The identical procedure was followed with the two groups in the word-fragment condition. All subjects were then given a filler task: Each subject was given a map of the United States and instructed to fill in the names of each state in the

Correspondence may be sent to Lawrence M. Schoen, who is now at the Department of Psychology, Lake Forest College, Lake Forest, IL 60045. time allowed. Upon completion of the filler task, the subjects were shown a practice slide of either an anagram or a word fragment, depending on the experimental condition. The subjects were informed that solving such word puzzles was not always easy and that they should not expect to be able to solve all or even most of them. They were further told not to continue working on a puzzle once it was off the screen. The subjects were then shown the series of 87 word puzzles and were instructed to write their solutions in the answer packets provided. The slides were presented in groups of 10 , allowing $10 \mathrm{sec}$ per slide with $30 \mathrm{sec}$ between groups. The answer packets consisted of 10 pages, each page containing 10 numbered answer blanks, giving the impression that there would be 100 word puzzles when in fact there were only 87 . The first 22 slides were filler items to allow the subjects to settle in and become familiar with the task. The next 56 slides were test items, half of these had been primed during the initial word presentation, depending upon the subjects' group. In this way, each of the two groups within a testing condition served as the control for the other. The final nine items were the remaining fillers.

\section{RESULTS}

A $2 \times 2$ analysis of variance with one between factor (measure type) and one within factor (primed vs. unprimed) was performed. As anticipated, both anagramsolution and word-fragment-completion rates were significantly higher in the primed conditions $[F(1,36)=$ $105.69, p<.001]$. However, there was no significant difference for the between factor (anagrams vs. fragments). Furthermore, despite the appearance of Figure 1, planned comparisons revealed no simple effects of type of measure at either primed $[F(1,55)=.63]$ or unprimed $[F(1,55)=1.93]$ levels. The comparisons do, however, show significant simple effects of priming for anagrams $[F(1,36)=33.55, p<.001]$ and for word fragments $[F(1,36)=75.27, p<.001]$.

\section{DISCUSSION}

At this point the picture is far from complete. Anagram solution does appear to be an adequate measure of implicit memory, but the effects are not as robust as those found with word-fragment completion. Although the differences are not significant, anagram solution appears 


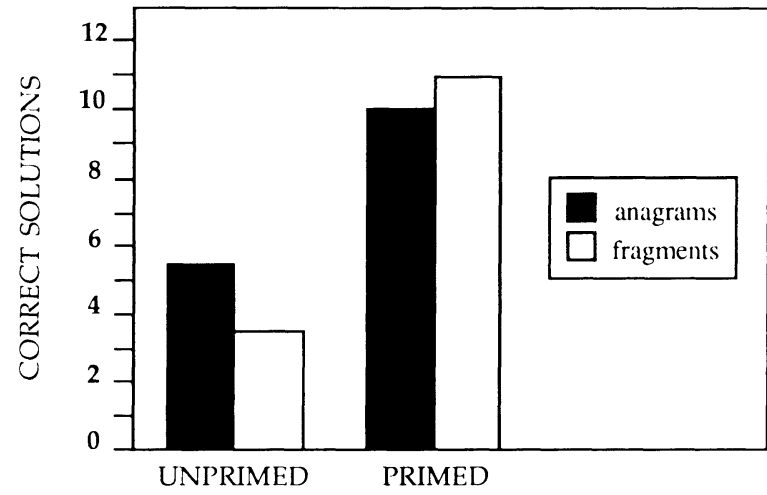

Figure 1. Mean anagram and fragment solution performance in primed and unprimed conditions.

to be higher than fragment completion in the unprimed condition, but lower than fragment completion when priming occurs. The precise reason for this is unclear. One possible explanation may lie in the data-driven nature of implicit-memory tasks (Graf, Shimamura, \& Squire, 1985). Consider that, in the fragment-completion task, the subjects were shown two-letter fragments and had to produce the remaining three letters to complete the word. That is, some basic structure was provided by the location of the two letters as well as by the phonological restrictions such locations hold for English words. However, in the case of anagram solution, all five letters were provided to the subjects, but no specific structure beyond general phonological restrictions was present. Viewed in this light, although anagram solution may still be seen as accessing what is basically a data-driven process, it may be of a very different sort than the more typical perceptual manipulations associated with such processes.
On the other hand, anagram solution may be more of a conceptually driven process, lacking any guiding structure, and would thus require greater lexical access before the subject could produce an answer. If the latter explanation is indeed the case, we would expect anagram solution to be facilitated by semantic priming as well as by simple presentation. Although this brief study does not even begin to address such questions, it does provide evidence for another measure of implicit memory and a different perspective on the phenomenon.

\section{REFERENCES}

GARDINER, J. M. (1988). Generation and priming effects in wordfragment completion. Journal of Experimental Psychology: Learning, Memory, \& Cognition, 14, 495-501.

Gibson, J. M., \& WATKINS, M. J. (1988). A pool of 1,086 words with unique two-letter fragments. Behavior Research Methods, Instruments, \& Computers, 20, 390-397.

Graf, P., Shimamura, A., \& SQuire, L. R. (1985). Priming across modalities and priming across category levels: Extending the domain of preserved function in amnesia. Journal of Experimental Psychology: Learning, Memory, \& Cognition, 11, 501-518.

Graf, P., SQuire, L. R., \& Mandler, G. (1984). The information that amnesic patients do not forget. Journal of Experimental Psychology: Learning, Memory, \& Cognition, 10, 164-178.

RoEDiger, H. L., III, \& BlaXton, T. A. (1987). Effects of varying modality, surface features, and retention interval on priming in wordfragment completion. Memory \& Cognition, 15, 379-388.

SCHACTER, D. L., \& Graf, P. (1986). Effects of elaborative processing on implicit and explicit memory for new associations. Journal of Experimental Psychology: Learning, Memory, \& Cognition, 12, $432-444$.

SCHOEN, L. M. (1988). The word-fragment completion effect: A computerassisted classroom exercise. Teaching of Psychology, 15, 95-97.

(Manuscript received May 5, 1989). 